\title{
East London Hospital for Children, Shadwell, 1868-1963. Queen Elizabeth Hospital for Children, Shadwell
}

\author{
VALENTINE A. J. SWAIN, F.R.C.S.; LILIAN WOODALL, B.A.
}

Brit. med. F., 1968, 4, 696-699

\section{Ratcliff Cross}

In the summer of 1866 , at the onset of the terrible scourge of Asiatic cholera in East London, Miss Sarah Goff and her sister volunteered to act as nurses, and it was there that she met Dr. Nathaniel Heckford (Fig. 1) and Dr. W. B. Woodman, who had volunteered from the London Hospital for the same cause. Later, on 28 January 1867, Sarah Goff, who was a student of medicine, and Dr. Heckford were married, and shortly after the cholera epidemic subsided they decided to start a children's hospital in East London. The sordid poverty of the children, the overcrowding, and the lack of sanitation emphasized the need for such a hospital. Their quest for a suitable building ended in the purchase of two old warehouses at Ratcliff Cross at the "exorbitant" price of $£ 2,000$. Here on their first wedding aniversary Dr. and Mrs. Heckford opened the East London Hospital for Children and Dispensary for Women (Figs. 2 and 3). Ten beds were provided, and in the first year there were 312 inpatients and 4,624 outpatients, a considerable number of whom were women. Infants under 2 years were also admitted. This was the first hospital in the country to do so.

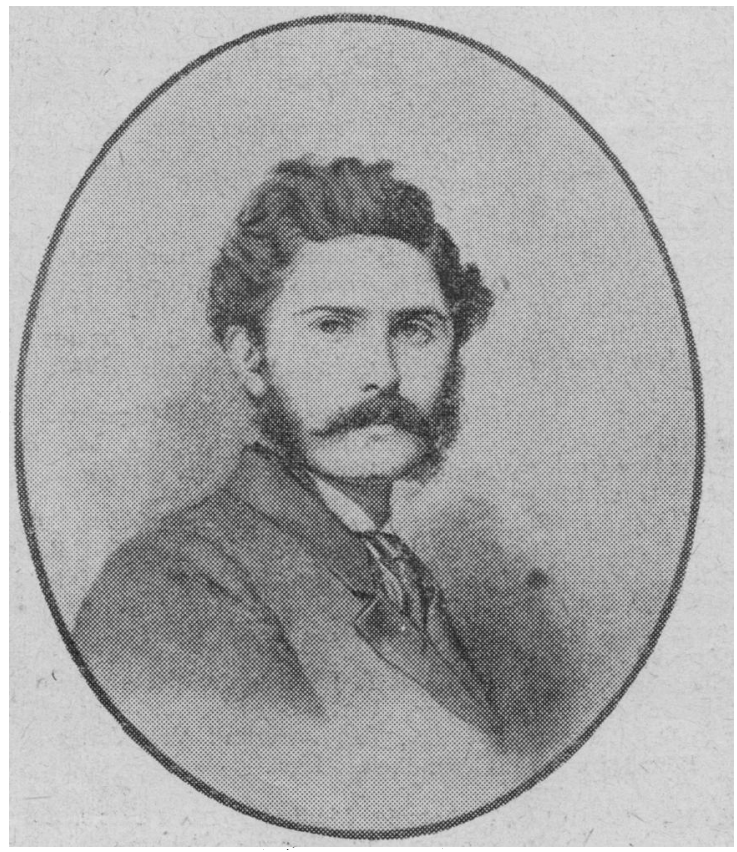

FIG. 1.-Dr. Nathaniel Heckford (1842-71).
The shortage of funds was serious, but visits to the hospital by Dr. Murray, Editor of the British Medical fournal, and later by Charles Dickens, stimulated medical and public interest in this institution. In an article on 19 December 1868 entitled "A small Star in the East" Dickens recounted how the 37 beds in the "airy, sweet and clean ward" were occupied by the sick children, and he remarked that "insufficient food and unwholesome living are the most frequent causes of disease

CHILDREN'S IIOSPITAL FOR EAST IONDON.

A childres's hospital has been started for the Fast of London; and not too soon. In that vast district, the London Hospital alone does the work of the Samaritan. "Somehow"-writes to us an accomplished physician who knows much of this quarter-" philanthropy, stimulated by enterprise, is infinitely more active at the West-end, where it seems to be universally admitted thirly or forty hospitals are not too many, whilst the poor East-end, with a million or more inhabitants, has to be content with two or three." If the good deeds done in Ormond.Street have not previously been emulated in Limehouse, it is not from want or earnestuess or goedwill, or the absence of sad need for their display, but because the funds and the organisation have hitherto been lacking. A small institution, with ten beds, has now been started by a gentleman, who has made himself responsible for the preliminary expenses, and who hopes to see the number increased to fifty (for which there is ample accommodation) by public liberality. There could hardly be a stronger claim on public generosity than that inherent in this enterprise. The medical staff will include Dr. Barnes, Mr. Buxton Shillitoe, Mr. Cowell, and Mr. Heckford, the latter gentleman as resident medical superintendent. A great part of the credit of bringing the charity into its present position is due to Mr. Heckford. There is every guarantet of good managemeint, and the certainty of skilful treatment. The hospital is direfully needed; and we trust that we shall soon hear that it is liberally supported.

FIG. 2.-Excerpt from British Medical fournal, 8 February 1868.

among the small patients." He described the plain furnishing, the hospital perambulator, the mongrel pet dog Poodles, the visiting by mothers on weekdays and by fathers on Sunday afternoons, and how the home circumstances were studied and recorded, and discharged patients were looked after and invited to come back to visit the hospital. The nurses, aged 19 to 24 years, had a comfortable dining-room and came from the near neighbourhood. Further publicity was given by the Illustrated London News, which printed a drawing of the Christmas party in 1868 and by Macmillan's Magazine (February 1870) in an article which described the hospital as " an Ark by the Riverside in the midst of a dreary sea of suffering and hunger and cold." 
Inspired by Heckford to establish a better hospital, a newly formed committee bought the freehold of its future site at Shadwell. But the promising beginning was clouded with tragedy, for Heckford developed consumption, which a stay at Amalfi failed to alleviate. He died on 14 December 1871, but he had lived to see plans for the foundation of the new

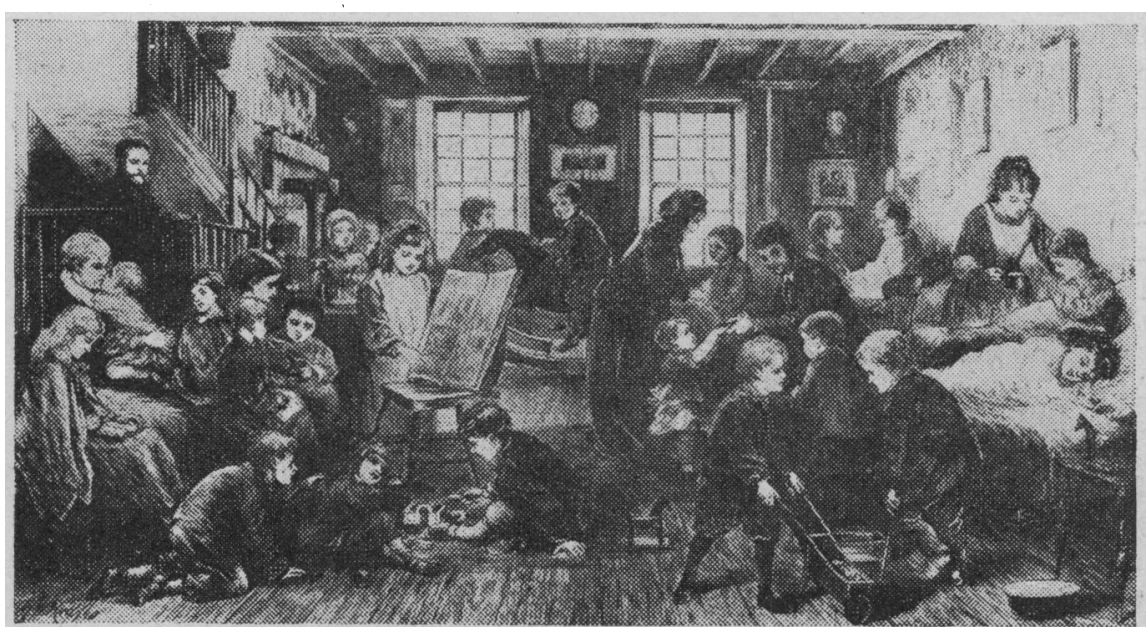

FIG. 3.-The East London Hospital for Children, from Illustrated London News, 27 April 1872 .

hospital, which was started in the summer of 1875 . His memorial was recorded in the Venetian mosaic tablet which is now on the wall of Heckford Ward in the Banstead branch.

Shortly after her husband's death Mrs. Heckford went abroad to undertake philanthropic work in various fields.

The establishment of special hospitals in the 1860 s was opposed and criticized in the medical journals, causing Heckford to state that ". . . special departments would practically be of no use but to passed men, who could just as easily attend special institutions, where they would learn more and where from the special influences and interests at work, the patients would gain morally and physically."

\section{Shadwell}

The foundation stone of the new hospital was laid by the Duke of Westminster in 1875 and two years later the new building (Fig. 4) was opened by H.R.H. the Duchess of Teck.
The occasion was celebrated in the locality as a general holiday; streets leading to the hospital were decorated and a guard of honour was provided by the Tower Hamlets Rifle Volunteers. The luncheon, with 400 guests, marked the occasion with loyal toasts and speeches. The cost of the building and land was about $£ 14,000$, but the hospital was opened free of debt. It was estimated that since the foundation of the Ratcliff Cross Hospital 50,000 to 60,000 patients were treated at the cost of $£ 4,500$ a year.

The hospital relied on the charity of many, for " no charge whatever was made for the inpatients or outpatients." Refreshments were sold in the waiting-room ; only children were admitted, but women merely requiring outpatient treatment were seen. In 1881 a further floor was added and in 1895, after alterations and renovations, the wards were reopened by the Duchess of Albany.

A contemporary report reads: "Amid the shades of grimy Shadwell, far removed from the main road, stands the East London Hospital for Children. It lies in the heart of the dreary dock districts of Tower Hamlets and from its position the maze of masts rising out of the Shadwell basin are clearly discernible. The hospital is indeed a haven to the children of the East. They come from the length and breadth of East London and, as though the crowded City of the Poor was not enough, they come from the equally dreary districts over the water of Rotherhithe and Deptford."

As the years went by various new services were provided. A convalescent home was opened at Bognor (1898) and additions at Shadwell included an electrical department (1902) and extensions to the outpatient department (1911). During the 1914-18 war the hospital maintained its much-needed services in face of many difficulties. In 1919 there was a temporary break in tradition with the appointment of women house officers. In the trade depression which followed the war the hospital was very short of funds ; the new nurses' home that was urgently needed was postponed from year to year. In 1932 the name was changed to "Princess Elizabeth of York Hospital for Children," and about this time it was clear to the committee that the premises were becoming obsolete. A building committee was formed, medical representatives including Dr. Leonard Findlay, Dr. Morley Fletcher, and $\mathrm{Mr}$. 
H. W. S. Wright. It was decided to build outside London " a country hospital for town children." A gift of a house and grounds at Banstead, Surrey, from Mr. A. Stanley Garton made it possible to proceed with plans for a 200-bed hospital, incorporating the existing mansion, and accommodation for 80 patients had been completed when war broke out. As electricity, water, and equipment were still lacking, other arrangements had to be made for Shadwell patients, and the building was let on lease, modified, and used for Service patients until 1946. Children were first admitted during 1947, and the Queen Elizabeth Hospital for Children at Banstead was officially opened in June 1948 by H.M. the Queen (then H.R.H. Princess Elizabeth).

During the 1939-45 war the building at Shadwell was not required as an emergency hospital, but it was put to a variety of uses. An outpatient service was maintained for children, and those requiring inpatient treatment were taken by car to the Bailey Convalescent Home at Bognor for the first few months. When the coast had to be evacuated in 1940 a temporary hospital was set up at Bayford in Hertfordshire, in the Manor House (the horne of Mr. and Mrs. F. Armitage Smith) and Ashendene. Gradually a few beds were made available in Shadwell. In 1942, however, the Board of Management had agreed to amalgamation with the Queen's Hospital for Children in Hackney Road, Bethnal Green, and beds were available there. Thus one governing body became responsible for paediatric services to children from a wide area of north and east London; and up to 1948, under the chairmanship of Brigadier General Sir Hill Child, and thereafter under Colonel J. K. Maitland, every effort was made to extend the hospital's services in direct child care, in the teaching of doctors and nurses, and in research.

With the implementation of the National Health Service in 1948 the Queen Elizabeth Group came under the control of the N.E. Metropolitan Regional Hospital Board. Fourteen years later, for economic reasons, it was decided that the hospital at Shadwell must close. However, the tradition of nearly a century will carry on in its sister hospitals in Hackney Road and in the Banstead branch. Shadwell had contributed much to the welfare of sick children-" not only those actually treated within its walls, but also countless others in Great Britain and overseas, who had profited from teaching given to mothers and children, from the training of sick children's nurses, medical students and doctors."

\section{Medical Staff}

Dr. Heckford, as the first resident medical superintendent, took a personal interest in the welfare of the patients and the nursing staff, and established regular postgraduate teaching at the hospital. Another member of the staff in 1868 at Ratcliff Cross was Dr. George Barnes, who later became a well-known obstetrician. With him was Mr. Buxton Shillitoe, who served as surgeon until his death in 1916. Also on the staff was $\mathrm{Mr}$. George Cowell (1836-1927), as surgeon; he was one of the last surgeons to undertake eye as well as general surgery. The above-mentioned three later became members of the consulting staff of the hospital at Shadwell.

In the early days (Sir) Andrew Clark (1826-93) of the London Hospital and (Sir) Samuel Wilks (1824-1911) of Guy's were both on the consulting staff of the hospital. Dr. Elizabeth Garrett, a former pupil of Heckford, became one of the visiting physicians from 1870 to 1873 . This pioneer appointment of a woman to the hospital's honorary staff had a romantic sequel, for a friendship arose between Dr. Garrett and Mr. J. G. S. Anderson, vice-chairman of the hospital, ending in the partnership of a happy marriage.

Early in the 1870 s Dr. Eustace Smith was appointed physician, joining Dr. John Mitchell Bruce on the staff. He soon became senior physician, and actively served the Shadwell Hos- pital in this capacity for nearly half a century. Eustace Smith was a precise clinician, and had a "perennial vigour of mind." His books On Wasting Diseases of Infants and Children (1868), Practical Treatise on Disease in Children (1889), and Common Remedies saw many editions. After his death he was acclaimed by his followers as " a rightful doyen of his favourite speciality."

In 1874 (Sir) Bryan Donkin became assistant physician at the hospital, where he joined his former chief and friend, Eustace Smith, for the next 24 years. Donkin's book Diseases of Childhood (Medical) was based on his medical practice at Shadwell and the Westminster Hospital. His interest in the delinquent child and the inheritance of medical characteristics is seen in his writing and career, for in 1898 he retired from Shadwell and became H.M. Commissioner of Prisons and Medical Adviser to the Prison Commission. Later, in 1915, he was appointed Director of Convict Prisons until his death in 1927.

In the 1880 s Dr. J. A. Coutts (1851-1911) joined the staff as assistant physician. He was a remarkable diagnostician who " had the unpleasant habit of being in the right." He was a reluctant speaker, but an able writer; he made contributions about inherited syphilis and functional neurosis of children. He was a loyal friend to the hospital, and during his last 12 years as physician "Shadwell had his best years and his wholehearted devotion." During this period Dr. Dawson Williams, who became Editor of the British Medical fournal, was one of his fellow physicians at the hospital.

On the surgical side, Mr. Robert William Parker became assistant surgeon at Shadwell in 1876. His two publications, Tracheotomy and its After Treatment (1880) dedicated to his former teacher Dr. Charles West-and Pathology and Etiology of Congenital Club Foot, reflect some of his experience in children's surgery. His legacy of a tracheotomy tube and a tenotome still appears in surgical instrument catalogues. " $\mathrm{He}$ was one of Shadwell's worthies," and retired in 1912 to live in Munich and Paris with his wife, who was a former Shadwell nurse, until his death in 1913.

Many of the physicians and surgeons served their earlier years at Shadwell before becoming more actively engaged in their teaching hospital, and some embarked on special branches of medicine, such names as W. H. Battle, H. B. Robinson, H. Morley Fletcher, (Sir) Cuthbert Wallace, R. Warren, A. Milne Gossage, Clive Riviere, J. E. H. Roberts, Somerville Hastings, R. P. Rowlands, Theodore Fisher, Wilfred Trotter, W. H. Bowen, and others.

One of the earliest specialist appointments was that of $\mathrm{Mr}$. $T$. Bird as administrator of anaesthetics in 1879. Later there were others such as E. Graham Little and J. F. M. Wigley as dermatologists, H. P. Winsbury White as urologist, and T. Pomfret Kilner as plastic surgeon.

The high calibre of the medical work and nursing gave the hospital an international reputation, and its special paediatric training attracted many doctors and nurses who later achieved prominence in paediatrics.

\section{Nursing Staff}

When the hospital opened with 10 beds, Mrs. Heckford, with her nursing and medical experience, naturally acted as matron. The nurses were given careful practical training, and several of the early staff took responsible posts elsewhere later in their careers. In 1871, when Mrs. Heckford had ceased to live at the hospital, Mrs. Fisher was appointed matron, but her post was mainly a housekeeping one. With the transfer to the new building it was no longer possible to run the hospital like a large private house, and Miss Mackenzie, from St. Thomas's Hospital, was appointed to be lady superintendent in charge of the nurses. She soon obtained promotion to a larger hospital, but some of her successors made their impact over a much longer period. The most important were Miss Frances 
Davies (1885-95), Miss Adelaide Row (1895-1917), and Miss Agnes M. Coulton (1917-41).

Miss Row herself had trained at Shadwell in 1883-4, and she had a great influence on the work carried on there. She was held in high regard by all grades of staff.

Miss Coulton was anxious for the recognition of sick children's nursing as a separate training, and served on the General Nursing Council. After the establishment of the Register of Sick Children's Nurses in 1921 she was a founder member of the Association of Sick Children's Hospital Nurses (now the Association of British Paediatric Nurses). But she was deeply concerned with her own nursing staff. Dr. Geoffrey Bourne wrote of the East London Hospital about 1930: "The standard of nursing in the wards of Shadwell in my opinion, and in the opinion of others better qualified to know, was then superior to that of any other children's hospital in London." Miss Coulton took an active part in the planning of the new branch at Banstead, which she had hoped to see open before she retired in 1939. She continued in office until 1941, and was succeeded by Miss I. G. Robertson, who was later matron of the Queen Elizabeth Hospital for Children.

Nursing at Shadwell owed much to the senior staff, who through the years maintained a high tradition of service. The new joint training schemes being evolved to meet today's new problems and ideas will broaden the nurses' experience, but will inevitably lessen the feeling of "belonging" to any particular training school. A new and different chapter in the story of nursing has opened.

\section{Patrons and Presidents}

The first royal visit was in 1877, when H.R.H. the Duchess of Teck opened the new hospital in Shadwell. In 1881 she and Princess Louise, and in 1886 Queen Victoria, consented to become patrons. Thereafter the reigning monarch and other members of the royal family gave their patronage up to 1942 . The various religious denominations were also represented on the list of patrons.

The first president of the hospital was Viscount Enfield (later Earl of Strafford), who served from 1869 until his death in March 1898. He was followed by the Duke of Portland, from 1898 to 1940 . There was no new appointment until the amalgamation with the Queen's Hospital in 1942, when Lord Iliffe was the first president of the Queen Elizabeth Hospital for Children. He was succeeded by H.R.H. the Princess Elizabeth.

\section{Administration}

Those concerned with the management of voluntary hospitals up to 1948 had a dual responsibility. Funds had to be raised before plans for development could go forward. Chairmen, treasurers, and committee members became personally involved, as did their wives and families, and friends. Tribute should be paid to the chairmen-Mr. Thomas Charrington (1875-87), Mr. Charles Cheston (1887-91), Mr. H. W. Trinder (18921901), Colonel Charles Needham (1901-14), Mr. Harry Machin (1914-31), and Brigadier General Sir Hill Child (1932-42), but it would be impossible and invidious to try to list all those others who helped during this long period.

An active Ladies' Association was established in 1899 and flourished until 1942. In 1938, with Princess Elizabeth as its president, the Children's League was founded to raise funds, particularly for the Banstead enterprise. This is still flourishing.

The day-to-day work of secretary was first performed in an honorary capacity by the Rev. S. B. Burnaby, the Rector of Wapping. Later, in $1870, \mathrm{Mr}$. Ashton Warner was appointed at a salary of $£ 100$ p.a. and with a house in Arbour Square. He held the post for 20 years, during which he organized many successful festival dinners and other functions for the benefit of the hospital funds. Mr. Thomas Hayes served for 11 years before his appointment as clerk to the governors of St. Bartholomew's Hospital in 1905. He was succeeded by Mr. W. M. Wilcox, who retired in 1932. In 1934 Sir Edward Penton was appointed. He had done much for the nursing profession, and in the years following devoted his energies to the planning and financing of the hospital at Banstead. He resigned in 1939 to join the Ministry of Supply, and Mr. F. J. Williams, who took over, returned from war service in time to be responsible for the completion of Banstead and its opening.

The hospital at Shadwell was demolished in 1967 to make way for urban development, and there a generation of children will live and will never know "the suffering, hunger, and cold" of Nathaniel Heckford's time a hundred years ago.

\section{BIBLIOGRAPHY}

Back, E. H., and Levin, S. (1954). Brit. med. F., 2, 406.

Bourne, G. (1963). We Met at Bart's. London.

Manton, Jo (1965). Elizabeth Garrett Anderson. London.

Swain, V. A. J. (1964). Med. Hist., 8, 136.

Swain, V. A. J. (1967). Brit. med. ₹., 4, 733. Queen Elizabeth Hospital for Children-A Commemorative Booklet,

The Story of an East London Hospital, 1904. London. 